\title{
Formation of massive dolomite of Lower Ordovician of Tarim Basin: evidences from $\mathrm{U}-\mathrm{Pb}$ dating
}

\author{
ZHANFENG QIAO ${ }^{1,}$ YANG LUO ${ }^{2}$
}

${ }^{1}$ CNPC Key Laboratory of Carbonate Reservoir, PetroChina Hangzhou Research Institute of Geology, Hangzhou 310023, qiaozf_hz@petrochina.com.cn

${ }^{2}$ PetroChina Southwest Oil \& Gasfield Company, China, 610058,xnluoyang@petrochina.com.cn

The origin of massive dolomite has been an enigma to geologists. More than $200 \mathrm{~m}$ thick dolomite of the Lower Ordovician, an important hydrocarbon reservoir, cropped out in Bachu area of Tarim Basin, Northwest China, and the recent developent of $\mathrm{U}-\mathrm{Pb}$ dating by laser ablation applied directly on thin sections make it possible to better understand the forming processes of massive dolomite. Based on the careful examination of outcrop and thin sections, the dolomite were classifed into fine to medium euhedral to subhedral crystalline dolomite with zonation under CL (FD), and coarse anhedral crystalline dolomite with dull core and bright edge and recognizable grainstone fabric within the core (CD). Both were performed the tests of laser ablated U-Pb dating and $\mathrm{C} \& \mathrm{O}$ isotopes, and ${ }^{87} \mathrm{Sr} /{ }^{86} \mathrm{Sr}$, and the dull core and bright edge of coarse dolomite were dated respectively.

The FDs get $\mathrm{U}-\mathrm{Pb}$ ages of $464 \pm 12 \mathrm{Ma}$ and $441 \pm 16 \mathrm{Ma}$, and $\mathrm{C}$ and $\mathrm{O}$ isotopes with the ranges of $0 \sim-4 \% 0$ and $-6 \sim-9 \% 0$ (VPDB). Dull cores of CD get 1 valuable age of $433 \pm 22 \mathrm{Ma}$, and bright edges of CD get 2 sets of valuable ages of $494 \pm 14$ $\mathrm{Ma}$ and $497 \pm 22 \mathrm{Ma}$, and $382 \pm 29 \mathrm{Ma}$, the cores have $\mathrm{C}$ and $\mathrm{O}$ isotopes with the ranges of $-1.7 \sim-1 \%$ and $-10 \sim-7 \%$ (VPDB). Both dolomite has similar ${ }^{87} \mathrm{Sr} /{ }^{86} \mathrm{Sr}$ ratios of $0.7092 \sim 0.7098$ higher than the value of contemporaneous seawater.

The petrological features and U-Pb dates and isotope compositions of FDs revealed that FDs probably formed firstly during penecontemporaneous stage and recrystallized during shallow burial of middle Ordovician to early Silurian, corresponding the burial depth of less than $1000 \mathrm{~m}$. whereas the fact that the $\mathrm{CD}$ with grainstone fabric and the $\mathrm{CD}$ crystals occurred between particles or along stylolites in grainstone have similar $\mathrm{CL}$ and isotope compositions suggests that $\mathrm{CD}$ formed directly by replacement of limestone during burial and most possibly during late Devonian of early Hercynian tectonic movement, during the Bachu uplift formed. The ages of bright edges of $\mathrm{CD}$ corresponding the middle Cambrian probably revealed the involvement of Cambrian formation fluids. This work revealed the massive dolomite formed by the multiple stages of dolomitization. 